\title{
PRODUÇÃO E RENDA BRUTA DA CEBOLINHA SOLTEIRA E CONSORCIADA COM NABO
}

\author{
Sandy Queiroz Espinoso ${ }^{1}$ \\ Samayana Inácio Delprete ${ }^{2}$ \\ Ariane Cardoso Costa ${ }^{3}$ \\ Magno do Carmo Parajara ${ }^{4}$ \\ Wallace Luís de Lima $^{5}$ \\ Arnaldo Henrique de Oliveira Carvalho ${ }^{6}$ \\ Fábio Luiz de Oliveira ${ }^{7}$
}

\begin{abstract}
Resumo: $O$ consórcio de plantas se apresenta como um dos métodos mais adequados à prática da olericultura. Objetivou-se com este trabalho avaliar a massa fresca e a renda bruta obtidas da cebolinha e do nabo em cultivo solteiro e em consórcio. Foi cultivado cebolinha(C) e nabo(N) em sistema de monocultivo e consorciado, com três arranjos $(75 \% \mathrm{C}+25 \% \mathrm{~N} ; 50 \% \mathrm{C}+50 \% \mathrm{~N}$ e $25 \% \mathrm{C}+75 \% \mathrm{~N})$, em parcela experimental de $3,0 \times 1,0 \mathrm{~m}$. Avaliou-se a produção de massa fresca e a renda bruta em cada sistema de cultivo por meio da quantificação da produção e multiplicação dessa pelo valor de venda do produto na central de abastecimento. Os consórcios foram avaliados pelo índice de eficiência de área (IEA). As produções médias foram superiores no monocultivo de cebolinha e de nabo, em relação aos consórcios. O IEA dos consórcio apresentou vantagem de aproveitamento de área nos cultivos $50 \% \mathrm{C}+50 \% \mathrm{~N}$ e $25 \% \mathrm{C}+75 \% \mathrm{~N}$, de 3 e $6 \%$, respectivamente. A renda bruta obtida pelo produtor foi maior no sistema de monocultivo para ambas as culturas. A partir da avaliação dos sistemas de cultivo solteiro e em consórcio, foi possível concluir que o cultivo solteiro de cebolinha e de nabo proporcionaram maiores produções de massa fresca em relação aos consórcios dessas culturas.
\end{abstract}

Palavras-chave: Brassica rapa var. rapa, Allium fistulosum, L.; Consórcio; Agroecologia.

\footnotetext{
${ }^{1}$ Instituto Federal do Espírito Santo - Campus de Alegre, Alegre-ES, Brasil. E-mail: sandyespinso@gmail.com.

2 Instituto Federal do Espírito Santo - Campus de Alegre, Alegre-ES, Brasil. E-mail: samayana97@gmail.com.

${ }^{3}$ Mestranda em Produção Vegetal/UENF, Brasil. E-mail: arianecardosocosta@hotmail.com.

${ }^{4}$ Graduando em Agronomia/Universidade Federal do Espírito Santo, Brasil. E-mail: magnocp1@hotmail.com.

5 Instituto Federal do Espírito Santo - Campus de Alegre, Alegre-ES, Brasil. E-mail: wallace@ifes.edu.br.

6 Instituto Federal do Espírito Santo - Campus de Alegre, Alegre-ES, Brasil. E-mail: acarvalho@ifes.edu.br.

7 Departamento de Produção Vegetal/ Professor - UFES - CCA, Brasil. E-mail: fabio.oliveira.2@ufes.br.
} 